\title{
Myocardial segmental thickness variability on echocardiography is a highly sensitive and specific marker to distinguish ischemic and non-ischemic dilated cardiomyopathy in new onset heart failure
}

\author{
Chandra K. Katikireddy ${ }^{1,2}$ [D $\cdot$ Tushar Acharya $^{1}$
}

Received: 11 October 2018 / Accepted: 15 December 2018 / Published online: 29 December 2018

(c) The Author(s) 2018

\begin{abstract}
The aim of this study was to determine non-invasive diagnostic markers by echocardiography that differentiate ischemic dilated (ICM) from non-ischemic dilated cardiomyopathy (NICM) in patients with new onset heart failure. We identified 100 consecutive new heart failure patients with dilated cardiomyopathy (valvular etiology excluded). Clinical risk factors, medication history, serum biomarkers, ECG and echocardiographic variables were compared between the ICM and NICM groups (as confirmed by coronary angiography). Mean age, left ventricular size and ejection fraction were 56 years, $6.1 \mathrm{~cm}$ and $26 \%$ respectively. A total of $24 \%$ had ICM. Patients with ICM were older (65 vs. 53 years; P $<0.001$ ). No significant difference was observed between ICM and NICM among 18 clinical variables, 7 laboratory tests, 6 EKG parameters and 10 of the 13 echocardiographic markers evaluated. Segmental wall thickness variability, regional wall motion abnormality and RV enlargement on echocardiogram (echo) differentiated ICM from NICM. Segmental thickness variability outperformed wall motion abnormality in diagnosing ICM with a sensitivity and specificity of 79.2 and $98.7 \%$ versus 62.5 and $84.2 \%$ respectively. RV enlargement was not sensitive but $90.6 \%$ specific for predicting NICM. Myocardial segmental thickness variability on echo, resulting from thinned infarcted or hibernating myocardium, is a highly sensitive and specific marker to differentiate ICM from NICM in new onset heart failure.
\end{abstract}

Keywords Cardiomyopathy $\cdot$ Echocardiography $\cdot$ Myocardial segmental thickness variability

$\begin{array}{ll}\text { Abbreviations } \\ \text { Echo } & \text { Echocardiogram } \\ \text { CAD } & \text { Coronary artery disease } \\ \text { ICM } & \text { Ischemic cardiomyopathy } \\ \text { LV } & \text { Left ventricle } \\ \text { NICM } & \text { Non-ischemic cardiomyopathy } \\ \text { RWMA } & \text { Regional wall motion abnormality } \\ \text { STV } & \text { Segmental wall thickness variability } \\ \text { RV } & \text { Right ventricle }\end{array}$

Chandra K. Katikireddy

katikireddy@gmail.com

1 Division of Cardiology, UCSF Fresno, 155 N Fresno St, Fresno, CA, USA

2 Division of Cardiology, VA Central California Health System, 2615 E. Clinton Ave, Fresno, CA 93703, USA

\section{Introduction}

Echocardiography (echo) constitutes initial diagnostic workup of patients presenting with new onset heart failure [1]. Further, echo helps to distinguish the pathological variants of cardiomyopathy $[1,2]$. Patients with dilated cardiomyopathy and systolic dysfunction on echo often undergo non-invasive myocardial ischemic stress testing or invasive coronary angiogram to evaluate for coronary artery disease (CAD) as underlying etiology [3]. Non-invasive tests to detect CAD such as stress myocardial perfusion imaging or cardiac computed tomography may not be able to distinguish ischemic vs. non-ischemic cardiomyopathy with high degree of confidence. An echocardiographic marker to diagnose ICM and facilitate appropriate patient selection before an invasive procedure would be desirable. Older studies have used regional wall motion abnormality (RWMA) assessment as a diagnostic marker for ICM with conflicting results [4-6]. Coronary obstruction not only affects segmental wall motion but also wall thickness, with infarcted or hibernating myocardial segments frequently appearing 
thinner compared to surrounding healthy myocardium. The diagnostic utility of segmental wall thickness on echo has not been systematically evaluated. The objectives of this study were to determine non-invasive markers (clinical, EKG and echo parameters) that would reliably distinguish ICM from non-ischemic cardiomyopathy (NICM) in patients with new onset heart failure. We specifically evaluated segmental thickness variability (STV) as a novel non-invasive diagnostic marker in the evaluation of ICM and evaluated its diagnostic performance compared to the gold standard of angiography.

\section{Materials and methods}

We retrospectively identified one hundred consecutive patients over a period of 3 years (2011-2014) admitted to a single center for new-onset systolic heart failure, who had dilated cardiomyopathy on echo (dilated left ventricle with an ejection fraction less than 40\%), and underwent angiographic evaluation for ICM. After excluding those with (1) known history of dilated cardiomyopathy; (2) previous diagnosis of heart failure (hospital admission, emergency room, or clinic visit); (3) previous diagnosis of CAD (history of stable angina pectoris, acute coronary syndrome, positive stress testing, obstructive CAD on angiography, coronary intervention, or coronary artery bypass surgery); (4) acute coronary syndrome presentation; and (5) missing echo or angiographic data; 118 patients were identified. Further, those with (6) severe primary valvular heart disease that could contribute to LV dilatation $(\mathrm{n}=2)$; (7) non-dilated cardiomyopathy (hypertrophic and restrictive cardiomyopathies with normal LV size) $(\mathrm{n}=9)$; and (8) poor quality echo images precluding accurate segmental wall thickness/ wall motion assessment $(n=7)$ were excluded. A total of 100 patients were included in the final analysis.

A thorough review of electronic medical records was conducted to collect demographics information, co-morbidities, clinical presentation, laboratory markers, pre-hospital medications, ECG, and the echo parameters at baseline. Myocardial segmental analysis was confirmed by the consensus read of two National Board of Echocardiography certified cardiologists. Investigators collecting baseline data and reviewing echo were blinded to the results of angiography. A single investigator, who was not involved in data collection, had access to angiography results. On the completion of data collection, this investigator categorized the patients into two groups (ICM and NICM) for statistical analysis. ICM was defined as severe $(\geq 70 \%)$ stenosis in the left anterior descending or a multi-vessel coronary distribution. NICM had no angiographic stenosis, mild to moderate coronary stenosis ( $<70 \%$ stenosis), or severe single-vessel stenosis in a coronary vessel other than the left main or left anterior descending artery [7] Degree of angiographic stenosis was based on the angiographer's interpretation adjudicated by the study investigators.

American heart Association's sixteen-segment model was used for regional left ventricular (LV) wall analysis [8-10]. Basal, mid, and apical slices of the parasternal short-axis were used for segmental wall thickness analysis [8]. Short axis views were obtained orthogonal to the long axis of the LV to avoid skewed measurements from oblique cuts. Papillary muscles and the right ventricular (RV) septal band were systematically excluded wherever possible. Segmental thickness variability (STV) was measured in end-diastole, on a per-patient basis, and defined as a ratio of thinnest to the thickest wall segment in a different coronary artery territory $[\mathrm{STV}=$ thinnest wall segment $(\mathrm{cm}) /$ thickest wall segment $(\mathrm{cm})]$. Based on this definition, no variability (equally thick walls) would ideally yield a ratio 1 . Based on preliminary analysis of the ICM cases, a cut-off value of 0.65 was used to define significant STV (Figs. 1, 2). Intra and inter-observer variability in the STV was estimated by two independent readers in 10 randomly selected subjects of ICM and 20 subjects of NICM.

RWMA was defined as per American Society of Echocardiography guidelines; hypokinesis, akinesis, dyskinesis, and aneurysmal segments were considered abnormal $[8,11]$. Isolated septal WMA in patients with RV pressure/volume overload, left bundle branch block, or ventricular pacing were not reported as WMA from ICM.

Cardiac chamber quantification and function was estimated per ASE guideline statement [8]. Biplane measurements used to estimate LVEF. LV dilatation was defined as

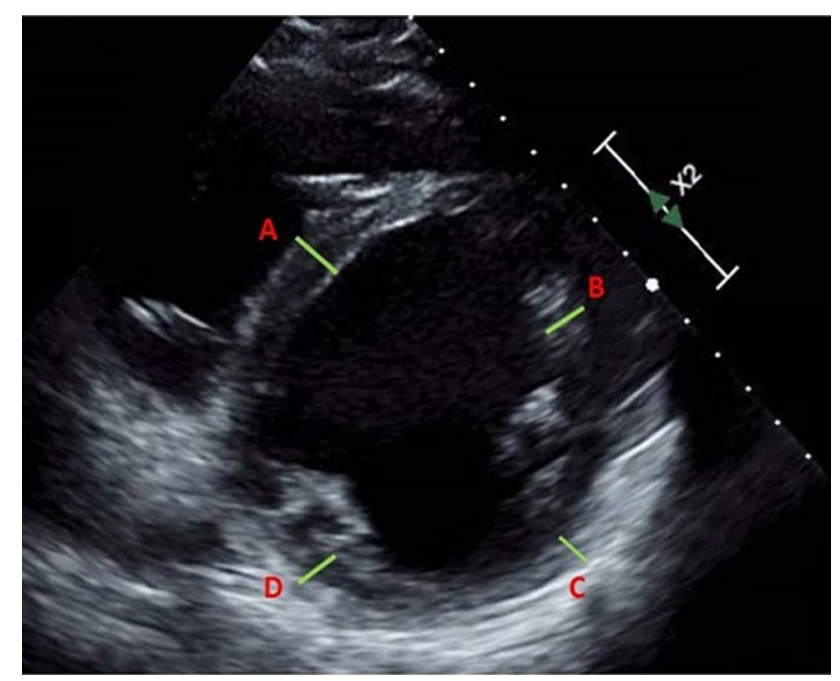

Fig. 1 A case of non-ischemic dilated cardiomyopathy presenting as new onset heart failure. Short axis view of the left ventricle demonstrating uniform myocardial segmental thickness $(9 \pm 1 \mathrm{~mm})$ and segmental thickness variability (STV) of $>0.65$ 


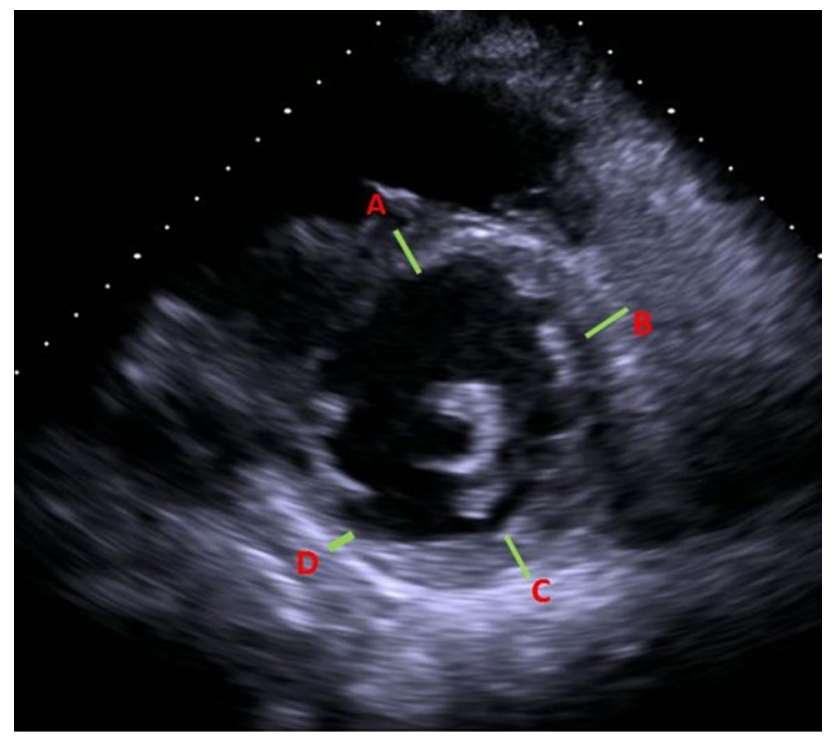

Fig. 2 A case of new onset heart failure from ischemic dilated cardiomyopathy. Short axis view of the left ventricle illustrating thinned inferior wall $(3 \mathrm{~mm})$ and relatively thicker other segments (septum; $7 \mathrm{~mm}$, anterior wall; $7 \mathrm{~mm}$; lateral wall; $8 \mathrm{~mm}$ ) in end diastolic phase with a segmental thickness variability (STV) of $<0.65$

LV end diastolic diameter (2D echo - parasternal long axis view) $>5.2 \mathrm{~cm}$ in females and $>5.8 \mathrm{~cm}$ in males. In addition to visual estimation, RV size was measured by RV end diastolic basal diameter in RV-focused apical 4-chamber view. Tricuspid annular planar systolic excursion (TAPSE), tissue Doppler derived tricuspid lateral annular systolic velocity $\left(\mathrm{S}^{\prime}\right)$ and 2D RV fractional area (FAC) change parameters were used to estimate RV systolic function.

\section{Statistical analysis}

Demographic, clinical, laboratory, ECG, and echo parameters were compared between the ICM and NICM groups. Continuous variables were reported as mean and standard deviation and discrete variables as percentage. Analysis of variance (ANOVA) and Chi square tests were used to compare these variables, respectively. A two-sided P-value less than 0.05 was considered statistically significant. Variables that were significantly different between the comparison groups were evaluated for their sensitivity, specificity, negative and positive predictive values, and diagnostic accuracy for the diagnosis of ICM with invasive coronary angiography as the gold standard. Receiver operating characteristic curve analysis was performed. The intra-class correlation coefficient (ICC) was calculated as a measure of the intraand inter-observer variability of the STV. A P value $<0.05$ was considered significant.

SPSS 20 (IBM SPSS statistics for Windows version 20.0 Armonk, New York) was used for all statistical analysis.

\section{Results}

The mean age of the study population was 56 years with $68 \%$ males. Mean LV size and LV ejection fraction were $6.1 \mathrm{~cm}$ and $26 \%$, respectively. A total of $24 \%$ had ICM confirmed by coronary angiogram. Patients with ICM were older (65 vs. 53 years) (Table 1). As expected, hypertension, hyperlipidemia, diabetes, and stroke were more prevalent with ICM. None of the NICM patients had obstructive CAD. Alcoholism and illicit drug use were more common in the NICM group pointing towards other potential etiological mechanisms of heart failure. However, these differences in baseline comorbidities did not reach statistical significance and therefore were not used for diagnostic test evaluation. Clinical presentation of the two groups was not statistically different either. Patients with ICM had less favorable lipid profile with higher total cholesterol and low-density lipoprotein levels. They had statistically higher mean troponin but similar BNP levels on presentation. They were more likely to be on antiplatelet agents and statin medications. ECG parameters showed no statistical differences.

Mean LV dimensions and systolic function was comparable between the two groups. Similarly, diastolic function and LA dimensions did not provide significant distinction. RV enlargement was more frequently seen in NICM patients ( 38 vs. $13 \%$; $\mathrm{P}=0.023$ ) but $\mathrm{RV}$ systolic function and RV systolic pressures were similar. Using the prespecified cut-off, significant STV was observed in $79 \%$ of ICM (mean STV 63\%) and only 1\% of NICM (mean STV $89 \%)(\mathrm{P}<0.001)$. ICM patients also had more RWMA than NICM patients (67 vs. $16 \%$; $<<0.001$ ).

Diagnostic test evaluations for STV, RWMA, and RV enlargement are elaborated in Table 2. STV outperformed RWMA and RV size in diagnosing ICM with a sensitivity and specificity of $79.2 \%$ and $98.7 \%$. RWMA was more specific $(84.2 \%)$ than sensitive $(66.7 \%)$. The most sensitive $(91.7 \%)$ way of identifying ICM on echo was to use the presence of either STV or RWMA (negative predictive value $96.9 \%$ ) as a diagnostic marker. On the other hand, the presence of both STV and RWMA made the test $100 \%$ specific for ICM with a positive predictive value of $100 \%$. STV had the overall highest diagnostic accuracy. Results of the receiver operating characteristic curve are shown in Fig. 3. Intra and inter observer variability for STV measurement in ICM and NICM were good. The ICC values were 0.90 (95\% CI 0.86-0.98), 0.92 (95\% CI 0.90\%-0.98) for intra observer variability and 0.84 (95\% CI $0.78-0.88$ ), 0.89 (95\% CI $0.82-0.92$ ) for inter-observer variability in ICM and NICM respectively. 
Table 1 Baseline characteristics of patients with new onset heart failure and dilated cardiomyopathy on echocardiography

\begin{tabular}{|c|c|c|c|}
\hline & $\begin{array}{l}\text { Non-ischemic dilated } \\
\text { cardiomyopathy }(n=76)\end{array}$ & $\begin{array}{l}\text { Ischemic cardio- } \\
\text { myopathy }(n=24)\end{array}$ & $\mathrm{P}$ value \\
\hline Age (years) & $53.20 \pm 14.43$ & $65.17 \pm 11.46$ & $<0.001$ \\
\hline Male & $51(67.11)$ & $17(70.83)$ & 0.086 \\
\hline \multicolumn{4}{|l|}{ Ethnicity } \\
\hline Caucasian & $11(14.47)$ & $5(20.83)$ & \multirow[t]{5}{*}{0.456} \\
\hline Hispanic & $38(50.00)$ & $7(29.17)$ & \\
\hline African-American & $8(10.53)$ & $4(16.67)$ & \\
\hline Other & $5(6.58)$ & $3(12.5)$ & \\
\hline Unknown & $14(18.42)$ & $5(20.83)$ & \\
\hline Body mass index & $29.26 \pm 7.06$ & $27.90 \pm 5.90$ & 0.392 \\
\hline \multicolumn{4}{|l|}{ Clinical presentation } \\
\hline Shortness of breath/orthopnea/PND & $59(77.63)$ & $23(95.83)$ & 0.064 \\
\hline Chest pain & $26(34.21)$ & $12(50.00)$ & 0.228 \\
\hline Edema/weight gain & $40(52.63)$ & $9(37.50)$ & 0.244 \\
\hline Duration of symptoms (days) & $18.88 \pm 26.43$ & $17.46 \pm 27.93$ & 0.821 \\
\hline Atrial fibrillation at presentation & $9(11.84)$ & $3(12.50)$ & 1.000 \\
\hline Heart rate at presentation & $101.65 \pm 19.92$ & $98.83 \pm 24.09$ & 0.568 \\
\hline Systolic blood pressure at presentation & $144.61 \pm 27.84$ & $136.75 \pm 25.94$ & 0.224 \\
\hline Diastolic blood pressure at presentation & $93.72 \pm 18.37$ & $84.67 \pm 20.43$ & 0.043 \\
\hline \multicolumn{4}{|l|}{ Co-morbidities } \\
\hline Hypertension & $51(67.11)$ & $20(83.33)$ & 0.196 \\
\hline Hyperlipidemia & $18(23.68)$ & $9(37.50)$ & 0.197 \\
\hline Diabetes mellitus & $30(39.47)$ & $14(58.33)$ & 0.156 \\
\hline Chronic kidney disease & $7(9.21)$ & $1(4.17)$ & 0.676 \\
\hline Chronic obstructive pulmonary disease & $7(9.21)$ & $1(4.17)$ & 0.676 \\
\hline Stroke/transient ischemic attack & $6(7.89)$ & $4(16.67)$ & 0.246 \\
\hline Peripheral vascular disease & $2(2.63)$ & $1(4.17)$ & 0.565 \\
\hline Smoking & $33(43.42)$ & $7(29.17)$ & 0.241 \\
\hline Alcoholism & $17(22.37)$ & $4(16.67)$ & 0.775 \\
\hline Substance abuse & $21(27.63)$ & $4(16.67)$ & 0.418 \\
\hline \multicolumn{4}{|l|}{ Laboratory markers } \\
\hline Total cholesterol & $137.20 \pm 35.05$ & $152.77 \pm 43.23$ & 0.095 \\
\hline Triglycerides & $99.47 \pm 53.72$ & $105.82 \pm 56.61$ & 0.638 \\
\hline High density lipoprotein & $36.36 \pm 15.10$ & $37.46 \pm 12.33$ & 0.760 \\
\hline Low density lipoprotein & $81.09 \pm 25.66$ & $94.14 \pm 33.68$ & 0.062 \\
\hline $\mathrm{BNP}$ & $1503.09 \pm 1555.80$ & $1284.33 \pm 1207.51$ & 0.556 \\
\hline Peak troponin & $0.12 \pm 0.21$ & $0.83 \pm 1.18$ & $<0.001$ \\
\hline Hemoglobin A1C & $6.99 \pm 1.99$ & $7.32 \pm 2.14$ & 0.526 \\
\hline \multicolumn{4}{|l|}{ Medications } \\
\hline Aspirin & $23(30.26)$ & $14(58.33)$ & 0.013 \\
\hline P2Y12 inhibitors & $1(1.32)$ & $4(16.67)$ & 0.011 \\
\hline Beta-blockers & $23(30.26)$ & $10(41.67)$ & 0.327 \\
\hline Angiotensin converting enzyme-inhibitors & $19(25.00)$ & $13(54.17)$ & 0.012 \\
\hline Angiotensin receptor blockers & $6(7.89)$ & $2(8.33)$ & 1.000 \\
\hline Thiazides & $5(6.58)$ & $2(8.33)$ & 0.672 \\
\hline Calcium channel blockers & $4(5.26)$ & $2(8.33)$ & 0.628 \\
\hline Other anti-hypertensive medications & $10(13.16)$ & $3(12.50)$ & 1.000 \\
\hline Insulin & $15(19.74)$ & $4(16.67)$ & 1.000 \\
\hline Oral hypoglycemic agents & $9(11.84)$ & $5(20.83)$ & 0.314 \\
\hline Statins & $15(19.74)$ & $12(50.00)$ & 0.007 \\
\hline
\end{tabular}


Table 1 (continued)

\begin{tabular}{|c|c|c|c|}
\hline & $\begin{array}{l}\text { Non-ischemic dilated } \\
\text { cardiomyopathy }(n=76)\end{array}$ & $\begin{array}{l}\text { Ischemic cardio- } \\
\text { myopathy }(n=24)\end{array}$ & $\mathrm{P}$ value \\
\hline \multicolumn{4}{|l|}{ EKG parameters } \\
\hline Q waves & $9(12.00)$ & $5(20.83)$ & 0.318 \\
\hline QRS duration & $110.56 \pm 22.80$ & $116.17 \pm 27.80$ & 0.323 \\
\hline Poor R-wave progression & $35(46.67)$ & $12(50.00)$ & 0.818 \\
\hline Left bundle branch block & $5(6.67)$ & $1(4.17)$ & 1.000 \\
\hline Right bundle branch block & $8(10.67)$ & $4(16.67)$ & 0.477 \\
\hline Non-specific IVCD & $12(16.00)$ & $8(33.33)$ & 0.082 \\
\hline \multicolumn{4}{|l|}{ Echo parameters } \\
\hline Left ventricular ejection fraction $(\%)$ & $25.61 \pm 6.90$ & $26.04 \pm 7.77$ & 0.797 \\
\hline \multicolumn{4}{|l|}{ Diastolic dysfunction } \\
\hline Grade 1 & $9 / 74(12.16)$ & $1(4.35)$ & 0.443 \\
\hline Grade $2-3$ & $58 / 74(78.38)$ & $19(82.61)$ & 0.775 \\
\hline Left ventricular cavity size in diastole $(\mathrm{cm})$ & $6.10 \pm 0.90$ & $5.9817 \pm 0.81$ & 0.559 \\
\hline Left atrial diameter $(\mathrm{cm})$ & $4.62 \pm 0.84$ & $4.36 \pm 0.47$ & 0.146 \\
\hline Mean segmental thickness variability ${ }^{\mathrm{a}}$ & $0.89 \pm 0.08$ & $0.63 \pm 0.15$ & $<0.001$ \\
\hline Segmental thickness variability & $1(1.32)$ & $19(79.17)$ & $<0.001$ \\
\hline Regional wall motion abnormality & $12(15.79)$ & $16(66.67)$ & $<0.001$ \\
\hline Right ventricular enlargement & $29(38.16)$ & $3(12.50)$ & 0.023 \\
\hline Right ventricular dysfunction & $36(47.37)$ & $9(37.50)$ & 0.483 \\
\hline RV systolic pressure & $41.86 \pm 13.81$ & $39.44 \pm 16.02$ & 0.526 \\
\hline Ventricular thrombus & $4(5.26)$ & $4(16.67)$ & 0.092 \\
\hline \multicolumn{4}{|l|}{ Mitral regurgitation } \\
\hline Mild & $46(60.53)$ & $16(66.67)$ & 0.638 \\
\hline Moderate to severe & $17(22.37)$ & $6(25.00)$ & 0.786 \\
\hline \multicolumn{4}{|c|}{ Mechanism for moderate to severe mitral regurgitation } \\
\hline Annular dilatation & $5 / 15(33.33)$ & $5 / 6(83.33)$ & 0.063 \\
\hline Restrictive leaflet motion & $10 / 15(66.67)$ & $1 / 6(16.67)$ & \\
\hline Pericardial effusion & $18(23.68)$ & $8 / 24(33.33)$ & 0.424 \\
\hline
\end{tabular}

$P N D$ paroxysmal nocturnal dyspnea, IVCD intra-ventricular conduction delay

${ }^{a}$ Segmental thickness variability $(\%)=$ thinnest wall segment $(\mathrm{cm}) /$ thickest wall segment $(\mathrm{cm})$

Table 2 Diagnostic test evaluation for select echocardiographic predictors of ischemic cardiomyopathy

\begin{tabular}{|c|c|c|c|c|c|}
\hline & Sensitivity (\%) & Specificity (\%) & $\begin{array}{l}\text { Positive predic- } \\
\text { tive value }(\%)\end{array}$ & $\begin{array}{l}\text { Negative predic- } \\
\text { tive value }(\%)\end{array}$ & Accuracy $(\%)$ \\
\hline Segmental thickness variability (STV) & 79.17 & 98.68 & 95 & 93.75 & 94 \\
\hline Regional wall motion abnormality (RWMA) & 66.67 & 84.21 & 57.14 & 88.89 & 80 \\
\hline STV or RWMA & 91.67 & 82.89 & 62.86 & 96.92 & 85 \\
\hline STV and RWMA & 54.17 & 100 & 100 & 87.36 & 89 \\
\hline Normal right ventricular size & 87.5 & 38.16 & 30.88 & 90.63 & 50 \\
\hline
\end{tabular}

\section{Discussion}

Heart failure is a frequently diagnosed condition and a common cause of significant morbidity and mortality [12]. A thorough initial work up to identify the underlying etiology can have prognostic and therapeutic implications.
Certain phenotypes, like ICM, have higher mortality than other groups [1,13,14].

To distinguish ICM from NICM, ACCF/AHA heart failure guidelines suggest that coronary angiogram be performed in patients presenting with de novo heart failure (Class IIA, level of evidence: C) [15]. However, the use of angiography as a 'rule-out' tool has low diagnostic yield 


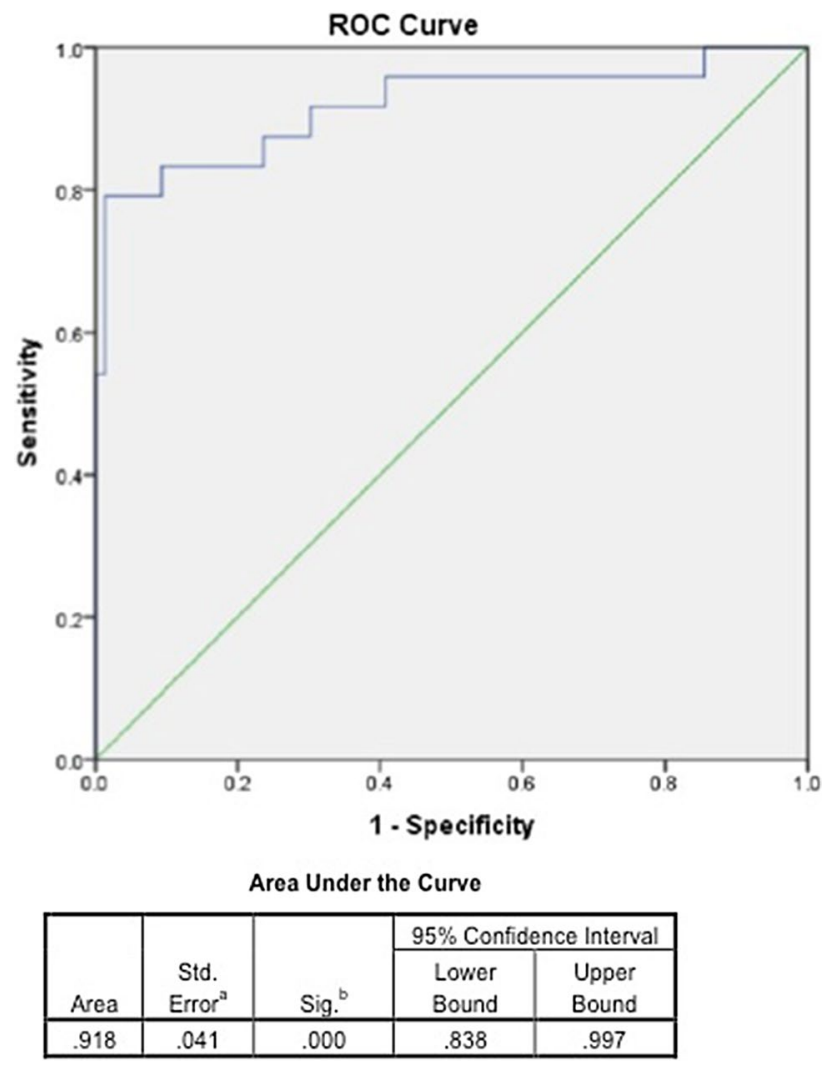

Fig. 3 Receiver operator curve analysis showing the performance of segmental thickness variability ratio from echocardiography to distinguish ischemic from non-ischemic dilated cardiomyopathy as confirmed by coronary angiogram

in these patients. Though ICM is the most prevalent form of dilated cardiomyopathy, the majority of these patients present with angina or myocardial infarction and only a few as de novo heart failure [16, 17]. In a study by Felker et al. among 1230 heart failure patients referred for endomyocardial biopsy, less than $10 \%$ were found to have ICM [1, 14]. In a recent study comparing MRI and angiography to distinguish ICM and NICM, ICM was reported in 22-26\% of de novo HF patients [18]. In the current study, we found ICM, as defined by angiogram, in $24 \%$ of new heart failure patients, falling within the general range of previously published data. Given this low incidence, finding a reliable pre-catheterization test to stratify patients based on likelihood of having ICM could prevent invasive testing in many. Low probability patients could instead be evaluated with a non-invasive modality (also a Class IIA recommendation) to exclude ischemic etiology.

In this study, we evaluated 18 clinical variables, 7 laboratory tests, 6 EKG parameters, and 13 echocardiographic markers with the goal of finding a diagnostic market that would reliably distinguish ICM from NICM (Table 1). As expected, patients with ICM were significantly older mirroring the prevalence of CAD. They had more prevalent clinical risk factors like hypertension, diabetes and hyperlipidemia (with higher levels of total cholesterol and LDL). However, these differences did not reach statistical significance and thus were insufficient in providing classification advantage in the 100 patients studied. Similarly, EKG findings could not distinguish the two groups. These findings suggest that a pre-test probability evaluation for underlying coronary artery disease based on risk factor and clinical presentation may not be feasible in new heart failure patients.

Wall motion is a dynamic motion of the ventricular wall in systole and diastole that may be impaired by ischemia/ infarction resulting in RWMAs. Wall thickness, on the other hand is more objective as measured at a single point in time, such as end systole or end-diastole. We measured end-diastolic wall thickness in this study as end-diastole represents true resting physiologic state of the myocardium. End-systolic measurement may be more prone for artefactual errors due to inclusion of the adjacent structures such as chordae and papillary muscle. Mechanisms of ischemic wall thinning are well described. Myocardial infarction causes myocyte necrosis and replacement with collagen scar resulting in thinning of the wall in the distribution of culprit coronary vessel $[19,20]$. Similarly, in severe ischemia leading to hibernating myocardium, the wall in the affected territory thins out from loss of contractile elements and dedifferentiation, whereas surrounding segments may undergo compensatory hypertrophy and remodeling [21-24]. The resulting difference in segmental thickness is more obvious and may be unique to ICM and can be evaluated and interpreted as the STV ratio. We found an STV ratio of $<0.65$ to have excellent predictive value for ICM with $92 \%$ area under the curve (Fig. 1).

We systemically evaluated pre-angiographic non-invasive markers in new onset heart failure with dilated cardiomyopathy and found the presence of STV, RWMA, and normal RV size on echo to correspond to coronary vascular etiology. Among these parameters, STV by itself was the most sensitive and specific diagnostic marker of ICM with a predictive accuracy of 94\%. Using STV in conjunction with RWMA could further increase the diagnostic test performance of STV. Visualization of either STV or RWMA could increase the sensitivity of identifying ICM, whereas the presence of both STV and RWMA in a patient made the test $100 \%$ specific for ICM. RV enlargement was found to be a sensitive but non-specific marker for NICM (Table 2).

To our knowledge, this is the first study to report STV on echocardiography as a diagnostic marker of ICM. RWMA on the other hand has been studied previously, albeit with disparate findings [4-6]. In the current study, we found regional wall motion abnormalities to be $67 \%$ sensitive and $84 \%$ specific in diagnosing ICM. These differences highlight 
the subjective nature of wall motion analysis with significant inter-user variability. Additionally, it is widely known that RWMA can result not only from coronary ischemia but a number of other conditions such as primary myopericardial disease [25-29]. To increase specificity for ICM, we did not report septal abnormalities from right ventricular pressure/ volume overload, left bundle branch block or ventricular pacing. Even still, RWMA was outperformed by STV.

Our study has a few limitations. The use of coronary angiography as the reference standard for distinguishing the cardiomyopathies may be a potential limitation. Further studies are needed to assess the reproducibility of this single center experience with a small number of patients and overcome potential reader bias in the interpretation of segmental wall analysis. Our study findings are not applicable to patients with suboptimal echo image quality from poor ultrasongraphic windows and technique. This may be overcome partially with the use of echocardiographic contrast agent. Prospective validation of this retrospective study would be desirable.

\section{Conclusions}

Dilated cardiomyopathy is a common disease process in patients presenting with new onset heart failure. In this patient population, STV as estimated by transthoracic echocardiography can accurately distinguish ICM from NICM. RWMA in isolation is a less accurate marker to make this distinction. Used in conjunction, these two parameters can reliably delineate ICM from NICM.

These echocardiographic markers to distinguish the underlying etiology of new onset heart failure may provide additional guidance to cardiac imagers and clinicians and guide appropriate therapy.

Acknowledgements We thank Drs. M. Singh, D. Le, K. Muhyieddeen, S.Venepally, B. Khatri and C. Rajyaguru for their assistance with collection of the database and statistical analysis.

\section{Compliance with ethical standards}

Conflict of interest The authors declare that they have no competing interest.

Open Access This article is distributed under the terms of the Creative Commons Attribution 4.0 International License (http://creativeco mmons.org/licenses/by/4.0/), which permits unrestricted use, distribution, and reproduction in any medium, provided you give appropriate credit to the original author(s) and the source, provide a link to the Creative Commons license, and indicate if changes were made.

\section{References}

1. Yancy CW, Jessup M, Bozkurt B, Butler J, Casey DE Jr, Drazner MH, Fonarow GC, Geraci SA, Horwich T, Januzzi JL, Johnson MR, Kasper EK, Levy WC, Masoudi FA, McBride PE, McMurray JJ, Mitchell JE, Peterson PN, Riegel B, Sam F, Stevenson LW, Tang WH, Tsai EJ (2013) Wilkoff BL 2013 ACCF/AHA Guideline for the Management of Heart Failure: A Report of the American College of Cardiology Foundation/American Heart Association Task Force on Practice Guidelines. J Am Coll Cardiol 62(16): e147-e239

2. Douglas PS, Garcia MJ, Haines DE, Lai WW, Manning WJ, Patel AR, Picard MH, Polk DM, Ragosta M, Ward RP, Weiner RB (2011) Appropriate Use Criteria for Echocardiography: A Report of the American College of Cardiology Foundation Appropriate Use Criteria Task Force, American Society of Echocardiography, American Heart Association, American Society of Nuclear Cardiology, Heart Failure Society of America, Heart Rhythm Society, Society for Cardiovascular Angiography and Interventions, Society of Critical Care Medicine, Society of Cardiovascular Computed Tomography, and Society for Cardiovascular Magnetic Resonance Endorsed by the American College of Chest Physicians. J Am Coll Cardiol 57(9):1126-1166

3. Patel MR, Bailey SR, Bonow RO, Chambers CE, Chan PS, Dehmer GJ, Kirtane AJ, Wann LS, Ward RP (2012) Appropriate Use Criteria for Diagnostic Catheterization: A Report of the American College of Cardiology Foundation Appropriate Use Criteria Task Force, Society for Cardiovascular Angiography and Interventions, American Association for Thoracic Surgery, American Heart Association, American Society of Echocardiography, American Society of Nuclear Cardiology, Heart Failure Society of America, Heart Rhythm Society, Society of Critical Care Medicine, Society of Cardiovascular Computed Tomography, Society for Cardiovascular Magnetic Resonance, and Society of Thoracic Surgeons. J Am Coll Cardiol 59(22):1995-2027

4. Medina R, Panidis IP, Morganroth J, Kotler MN, Mintz GS (1985) The value of echocardiographic regional wall motion abnormalities in detecting coronary artery disease in patients with or without a dilated left ventricle. Am Heart J 109(4):799-803

5. Chen YZ, Sherrid MV, Dwyer EM Jr (1985) Value of two-dimensional echocardiography in evaluating coronary artery disease: a randomized blinded analysis. J Am Coll Cardiol 5(4):911-917

6. Diaz RA, Nihoyannopoulos P, Athanassopoulos G, Oakley CM (1991) Usefulness of echocardiography to differentiate dilated cardiomyopathy from coronary-induced congestive heart failure. Am J Cardiol 68(11):1224-1227

7. Felker GM, Shaw LK, O'Connor CM (2002) A standardized definition of ischemic cardiomyopathy for use in clinical research. $\mathrm{J}$ Am Coll Cardiol 39:210-218

8. Lang RM, Badano LP, Mor-Avi V, Afilalo J, Armstrong A, Ernande L, Flachskampf FA, Foster E, Goldstein SA, Kuznetsova T, Lancellotti P, Muraru D, Picard MH, Rietzschel ER, Rudski L, Spencer KT, Tsang W, Voigt JU (2015) Recommendations for cardiac chamber quantification by echocardiography in adults: an update from the American Society of Echocardiography and the European Association of Cardiovascular Imaging. J Am Soc Echocardiogr 28(1):1-39

9. Schiller NB, Shah PM, Crawford M, DeMaria A, Devereux R, Feigenbaum H, Gutgesell H, Reichek N, Sahn D, Schnittger I (1989) Recommendations for quantitation of the left ventricle by two-dimensional echocardiography. J Am Soc Echocardiogr 2:358-367

10. Cerqueira MD, Weissman NJ, Dilsizian V, Jacobs AK, Kaul S, Laskey WK, Pennell DJ, Rumberger JA, Ryan T, Verani MS, American Heart Association Writing Group on Myocardial 
Segmentation and Registration for Cardiac Imaging (2002) Standardized myocardial segmentation and nomenclature for tomographic imaging of the heart: a statement for healthcare professionals from the Cardiac Imaging Committee of the Council on Clinical Cardiology of the American Heart Association. Circulation 105(4):539-542

11. Oh JK, Gibbons RJ, Christian TF, Gersh BJ, Click RL, Sitthisook S, Tajik AJ, Seward JB (1996) Correlation of regional wall motion abnormalities detected by two-dimensional echocardiography with perfusion defect determined by technetium $99 \mathrm{~m}$ sestamibi imaging in patients treated with reperfusion therapy during acute myocardial infarction. Am Heart J 131(1):32-37

12. Mozaffarian D, Benjamin EJ, Go AS, Arnett DK, Blaha MJ, Cushman M, de Ferranti S, Després JP, Fullerton HJ, Howard VJ, Huffman MD, Judd SE, Kissela BM, Lackland DT, Lichtman JH, Lisabeth LD, Liu S, Mackey RH, Matchar DB, McGuire DK, Mohler ER 3rd, Moy CS, Muntner P, Mussolino ME, Nasir K, Neumar RW, Nichol G, Palaniappan L, Pandey DK, Reeves MJ, Rodriguez CJ, Sorlie PD, Stein J, Towfighi A, Turan TN, Virani SS, Willey JZ, Woo D, Yeh RW, Turner MB, American Heart Association Statistics Committee and Stroke Statistics Subcommittee (2015) Heart disease and stroke statistics-2015 update: a report from the American Heart Association. Circulation 131(4):e29-e322

13. Bart BA, Shaw LK, McCants CB Jr, Fortin DF, Lee KL, Califf RM, O'Connor CM (1997) Clinical determinants of mortality in patients with angiographically diagnosed ischemic or nonischemic cardiomyopathy. J Am Coll Cardiol 30(4):1002-1008

14. Felker GM, Thompson RE, Hare JM, Hruban RH, Clemetson DE, Howard DL, Baughman KL, Kasper EK (2000) Underlying causes and long-term survival in patients with initially unexplained cardiomyopathy. N Engl J Med 342:1077-1084

15. Gheorghiade M, Sopko G, De Luca L, Velazquez EJ, Parker JD, Binkley PF, Sadowski Z, Golba KS, Prior DL, Rouleau JL, Bonow RO (2006) Navigating the crossroads of coronary artery disease and heart failure. Circulation 114(11):1202-1213

16. Lloyd-Jones DM, Larson MG, Leip EP, Beiser A, D'Agostino RB, Kannel WB, Murabito JM, Vasan RS, Benjamin EJ (2002) Levy D Lifetime risk for developing congestive heart failure: the Framingham Heart Study. Circulation 106:3068 - 3072

17. Assomull RG, Shakespeare C, Kalra PR, Lloyd G, Gulati A, Strange J, Bradlow WM, Lyne J, Keegan J, Poole-Wilson P, Cowie MR, Pennell DJ, Prasad SK (2011) Role of cardiovascular magnetic resonance as a gatekeeper to invasive coronary angiography in patients presenting with heart failure of unknown etiology. Circulation 124(12):1351-1360

18. Sutton MGJ, Sharpe N (2000) Left ventricular remodeling after myocardial infarction: pathophysiology and therapy. Circulation 101:2981-2988
19. Corya BC, Rasmussen S, Feigenbaum H, Knoebel SB, Black MJ (1977) Systolic thickening and thinning of the septum and posterior wall in patients with coronary artery disease, congestive cardiomyopathy, and atrial septal defect. Circulation 55(1):109-114

20. Borgers M, Thone F, Wouters L, Ausma J, Shivalkar B, Flameng W (1993) Structural correlates of regional myocardial dysfunction in patients with critically coronary artery stenosis: chronic hibernation?. Cardiovasc Pathol 2:237-245

21. Flameng W, Suy R, Schwarz F, Borgers M, Piessens J, Thone F, Van Ermen H, De Geest H (1981) Ultrastructural correlates of left ventricular contraction abnormalities in patients with chronic ischemic heart disease: determinants of reversible segmental asynergy postrevascularization surgery. Am Heart J 102(5):846-857

22. Ausma J, Schaart G, Thoné F, Shivalkar B, Flameng W, Depré C, Vanoverschelde JL, Ramaekers F, Borgers M (1995) Chronic ischemic viable myocardium in man: aspects of dedifferentiation. Cardiovasc Pathol 4(1):29-37

23. Carluccio E, Biagioli P, Alunni G, Murrone A, Giombolini C, Ragni T, Marino PN, Reboldi G (2006) Ambrosio G Patients with hibernating myocardium show altered left ventricular volumes and shape, which revert after revascularization: evidence that dyssynergy might directly induce cardiac remodeling. J Am Coll Cardiol 47(5):969-977

24. Wallis DE, O'Connell JB, Henkin RE, Costanzo-Nordin MR, Scanlon PJ (1984) Segmental wall motion abnormalities in dilated cardiomyopathy: a common finding and good prognostic sign. J Am Coll Cardiol 4(4):674-679

25. Grines CL, Bashore TM, Boudoulas H, Olson S, Shafer P, Wooley CF (1989) Functional abnormalities in isolated left bundle branch block. The effect of interventricular asynchrony. Circulation 79(4):845-853

26. Palmieri V, Okin PM, Bella JN, Gerdts E, Wachtell K, Gardin J, Papademetriou V, Nieminen MS, Dahlöf B, Devereux RB (2003) Losartan Intervention For End-point reduction in hypertension. Echocardiographic wall motion abnormalities in hypertensive patients with electrocardiographic left ventricular hypertrophy: the LIFE Study. Hypertension 41(1):75-78

27. Goitein O, Matetzky S, Beinart R, Di Segni E, Hod H, Bentancur A, Konen E (2009) Acute myocarditis: noninvasive evaluation with cardiac MRI and transthoracic echocardiography. AJR Am J Roentgenol 192(1):254-258

28. Seward JB, Casaclang-Verzosa G (2010) Infiltrative cardiovascular diseases: cardiomyopathies that look alike. J Am Coll Cardiol 55(17):1769-1779

29. Regueiro A, García-Álvarez A, Sitges M, Ortiz-Pérez JT, De Caralt MT, Pinazo MJ, Posada E, Heras M, Gascón J, Sanz G (2013) Myocardial involvement in Chagas disease: insights from cardiac magnetic resonance. Int J Cardiol 165(1):107-112 